American Journal of Pharmaceutical Education 2020; 84 (12) Article 8335.

\title{
COMMENTARY
}

\section{Rethinking Approaches to Succession Planning and Developing a Leadership Pipeline in Academic Pharmacy}

\author{
David G. Fuentes, PharmD \\ Editorial Board Member, American Journal of Pharmaceutical Education, Arlington, Virginia \\ Submitted August 11, 2020; accepted August 19, 2020; published December 2020.
}

Keywords: leadership, management, continuing professional development

Those in pharmacy education who have served in administrative and supervisory roles are fortunate to have been able to mentor and help faculty and staff members with their career trajectory. However, not all administrators with supervisory responsibilities see themselves as highly impactful in mentoring future talent and developing succession plans. This commentary is a call to all those serving as deans, department chairs, associate and assistant deans, and directors in their respective areas to take the lead and responsibility in the challenging work of developing talent and strong succession plans within your respective organization. With more US pharmacy programs than ever before, this is a critical time for pharmacy education leadership as executive teams need to fill their positions with exceptional leaders.

Developing talent is critical to succession planning in healthy organizations, but this is a calling that can bring about a great deal of stress and discomfort for some faculty members because it is not an easy task. This commentary can be specifically useful to those in department chair, managerial and supervisory administrative roles, and faculty and staff members. Leadership development and succession planning are instrumental to the sustainability of viable and effective leaders at all levels within an organization. Organizations often struggle with succession planning because of their approach and mindset. By limiting succession planning to simply replacing individuals or developing a select few within their higher leadership teams to take over when a key role is vacated, organizations can often fail to explore potential in other employees. ${ }^{1,2}$ Organizations across various industries are often left with costly leadership gaps and losses to both time and efficiency during the search and selection process. $^{1,3-5}$ Gaps in succession-planning processes also exist in pharmacy programs, where organizations suddenly find themselves managing unplanned vacancies. Even deliberate vacancies can result in organizational stress and anxiety about the future. ${ }^{3,6-8}$ While many

Corresponding Author: David G. Fuentes, Clovis, CA. pharmacy programs focus on the role of the chief executive officer (CEO) dean when they think about succession planning, leadership roles in all areas of the school need to be recognized to help organizations take honest stock of where additional leadership is most needed, and where it can be developed at all levels. ${ }^{1,9,10}$

In support of intentional succession planning, colleagues in pharmacy education, nursing, business, health care administration, and human resources have explored and examined current practices only to find a series of gaps to developing leaders that can best be remedied by using different approaches. ${ }^{6,7,9-12}$ Charan and colleagues challenge administrators to ensure that everyone within an organization has a clear job description of their roles and responsibilities and understand that they are instrumental to the organization's success. ${ }^{1}$ Charan and colleagues discuss the value of ensuring that all employees are working and producing at their appropriate level, not based on their total abilities but on their role within the organization. For example, a department chair or assistant dean forgoing administrative responsibilities to continue serving as a course director or teaching an inordinate number of hours in the classroom or practice site would illustrate an individual not working at their appropriate level. In this example, the individual may be a high performer in the classroom or as a preceptor, but still developing and growing as an administrator. Charan and colleagues offer that when an individual is in a state of stress and feeling overwhelmed in their leadership role, they seek to revert to areas of comfort, which many administrators in pharmacy education may identify as a retreat back to teaching, service, scholarship, or practice. ${ }^{1}$

Having served in academic roles across various established and emerging programs, I can attest to the challenges in finding and maintaining effective and sustainable mentorship. ${ }^{9,10,13}$ Both require time, energy, and patience on the part of the mentor as well as the mentee. ${ }^{14-16}$ In addition to mentorship skills, seasoned faculty members themselves often need help in distinguishing between mentoring, advising, sponsoring, and coaching as different 


\section{American Journal of Pharmaceutical Education 2020; 84 (12) Article 8335.}

approaches to engage diverse mentees equitably and strategically without falling into the common and ineffective pitfalls that can render them ineffective as leaders. ${ }^{3,4}$

In addition to the significance of mentorship in succession planning, strong personnel management is necessary to provide coaching and direction to individuals who may not be working at their highest potential and at the appropriate level. ${ }^{1,2,5,17,18}$ Strategies for managing performance and asking powerful questions are often components of business acumen developed over time that have applications and approaches rooted in both practice experience and neuroscience. ${ }^{3,5,19}$ Examples of powerful questions include probes into how employees spend their time, whether they are really tackling the responsibilities connected to their leadership role, and how often they retreat to conducting work that is comfortable vs work connected to their developing role and duties as a leader. Pharmacy administrators serving in supervisory roles need to embrace frank conversations with their employees at all levels about how they spend their time, the tasks and duties that energize them, and the responsibilities they tend to approach with procrastination and anxiety. ${ }^{1,19}$

When administrators serving in supervisory roles can approach their faculty and staff members with kindness, curiosity, and respect, then conversations can be enlightening to both supervisor and employee. Additionally, when administrators in supervisory roles can have conversations with their employees that identify both behavioral and mindset elements that hold them back from promotion, provide effective coaching and guidance, and then hold them accountable to mutually developed actions, people throughout the entire organization will be better equipped to grow. Understanding where each employee is thriving and where they need help developing can frame a supervisor's future efforts in encouraging the employee to prepare for appropriate leadership roles in the organization that resonate with their unique goals and desires.

Strategies for pharmacy programs to revise their approaches to succession planning can help them develop a pool of abundantly talented individuals at all levels, including moving superb individual contributors and performers into roles where they will supervise the work of others, and identifying those with the potential and talent to manage other managers and systems across functionally diverse offices and departments. ${ }^{1-3}$ This approach will require that all positions within the organization are carefully examined for clarity, desired performance metrics, and mechanisms for accountability. ${ }^{3,18}$ In academia, new administrators in supervisory roles may report challenges with having "difficult" conversations, holding faculty members accountable for issues related to civility and collegiality, and redirecting individuals away from "pet projects" towards other endeavors falling within their direct responsibilities, adding value to others, and contributing to the superordinate goals of the organization.

Helping current leaders accrue new skill sets in the areas of succession planning will include a holistic development and mindset shift to help them see succession planning as a duty to help create a sustainable organization. Five specific actions towards reimagined thinking for organizational leaders at all levels include: developing performance review processes and habits that make evaluation a formative and continuous process vs a yearly responsibility; creating an academic environment in which managers and employees can share open conversations about where time is spent and what types of tasks are being placed on hold in order to pursue more comfortable activities; promoting an environment that catapults individuals towards their highest potential, regardless of whether they aspire to a formal leadership role; recognizing the different leadership levels as a function of competencies vs simply focusing on rank, title, seniority, and other similar markers; and adopting an openness within the organization that allows those serving in supervisory roles and in employee roles to share their challenges and needs for help with one another while not succumbing to blame tactics or dysfunctional group dynamics.

Five specific calls to action for deans, department chairs, directors, and any other administrator or faculty member in a supervisory role include: instilling clarity into every role, task, and opportunity; promoting two-way communication so that efforts to help employees along the way are not misperceived as micromanagement or a lack of trust; sharing work assignments equitably, when possible, among all members of the departments or offices to avoid overwhelming employees who constantly say "yes" and agree to various projects; finding each individual's specific and unique motivating factors and creating the high-quality environment for allowing everyone to access their own source of intrinsic motivation; and engaging in uncomfortable, necessary conversations with disruptive, passive aggressive, or otherwise uncooperative employees.

Faculty and staff members who are in supervisory roles, as well as those not in supervisory roles, can engage in the following seven actions to help an organization in succession planning, including: willingly sharing their experiences, both positive and negative, with supervisors and mentors; seeking early assistance when faced with a stretch project or when taking on an assignment that may be unfamiliar; asking for collaboration or additional opinions on projects where needed before giving in to assumptions that it is only possible to find success alone; reaching out to both internal and external faculty members to develop a strong network of collaborators and advisors on scholarly projects 


\section{American Journal of Pharmaceutical Education 2020; 84 (12) Article 8335.}

and career development approaches; seeking out opportunities on committees and organizations to gain exposure to various programmatic and operational functions within the program; embracing a mentality that strives towards excellence rather than perfection, to maximize productivity and enhance both confidence and self-efficacy; and communicating clearly when finding oneself having negative thoughts about work that can lead to professional burnout.

Having served within various organizations as both a faculty member and administrator, it is possible for me to speak to the high learning curve and the intense crosstraining that occurs as everyone is asked to serve on almost every committee and in almost every initiative as the program and curriculum are developed. I have experienced a great deal of opportunity in these environments to learn and grow. Having experienced these environments and consulted for various established and emerging programs, I have observed that the challenges to succession seem to be ubiquitous. When facing the common challenges of lack of clarity among roles, unnecessary redundancies, opposing and counterculture confusions, and lack of understanding of the metrics for success, programs may often face challenges with reaching organizational health and thinking more strategically. External pressures from enrollment challenges, competition for finding key distinguishing factors, meeting accreditation standards in innovative ways, navigating effective operations during a pandemic, and finding strategies to document and communicate mission fulfillment are only a few of the obstacles that programs presently encounter. Regardless of how established or new the pharmacy program is, good leadership and solid succession plans are all areas where further help and assistance are being sought. This is both an area of need and an area of opportunity in the Academy at this time.

Succession planning is an important area in which pharmacy programs need to be very vigilant. Growing internal talent has the potential to help organizations retain individuals, promote growth as an organizational value, and save costs in recruitment, onboarding, and orientation. The courage to appropriately approach succession planning starts at the top of the organization and ideally will trickle down to the frontlines. Ensuring that every employee, whether a staff member, faculty member, or administrator, is functioning at the appropriate leadership level for their roles and responsibilities promotes organizational health and clarity. Because the role of succession planning is organizational in breadth and requires solid management and coordination among all employees, individuals in both supervisory and nonsupervisory roles have an opportunity to work collaboratively. The rewards of intentional and thoughtful succession planning would be great and would include higher employee retention rates, greater organizational clarity surrounding complex and interconnected roles and responsibilities, and more positive results to report to boards and stakeholders about faculty and staff development and achievement. Being thoughtful about the development of a strong leadership pipeline and succession planning will help as the Academy seeks exceptional leaders who can think strategically and nimbly to face new challenges we have never seen.

\section{REFERENCES}

1. Charan R, Drotter S, Noel J. The Leadership Pipeline: How to Build the Leadership Powered Company. Jossey-Bass; 2011.

2. Newstrom JW. Organizational Behavior: Human Behavior at Work. McGraw-Hill; 2016.

3. Block P. Flawless Consulting (2nd ed.). San Francisco, CA: Pfieffer; 1999.

4. Lussier RN, Achua CF. Leadership: Theory, Application, Skill Development. Mason, OH: Thomson/South-Western; 2004.

5. Schein EH. Organizational Culture and Leadership (4th ed.). San Francisco, CA: Jossey Bass; 2010.

6. Collins SK. Succession planning: perspectives of chief executive officers in US hospitals. Health Care Manager. 2009;28(3):258-263. 7. Redmond RW. Leadership succession planning. An evidencebased approach for manning the future. J Nurs Admin. 2006;36(6): 292-297.

8. Ready DA. How to grow great leaders. Harv Bus Rev. 2004; 82(12):92-100.

9. Plaza CM, Draugalis JR, Slack MK, et al. Administrative career planning: a ten-year update of the pharmacy deanship. Am J Pharm Educ. 2004;68(1):Article 8.

10. Plaza CM, Draugalis JR, Skrepnek GH, Slack MK. The role of administrative mentoring in the pharmacy issue deanship. Am J Pharm Educ. 2004;68(4):Article 86.

11. Young D. Effective leadership is vital to pharmacy's future. Am J Health-Syst Pharm. 2004;61(12):1212-1214.

12. Cohn JM, Khurana R, Reeves L. Growing talent as if your business depended on it. Harv Bus Rev. 2005;83(10):62-70.

13. Crumpacker M, Crumpacker JM. Succession planning and generational stereotypes: should HR consider age-based values and attitudes a relevant factor or a passing fad? Pub Pers Manag. 2007; 3(94):349-369.

14. Haines ST. The mentor-protégé relationship. Am J Pharm Educ. 2003;67(3):Article 82.

15. Fuller K, Maniscalco-Feichtl M, Droege M. The role of the mentor in retaining junior pharmacy faculty members. Am J Pharm Educ. 2008;72(2):Article 41.

16. Zeind CS, Zdanowicz M, MacDonald K, Parkhurst C, King C, Wizwer P. Developing a sustainable faculty mentoring program. Am J Pharm Educ. 2005;69(5):Article 100.

17. Cutler A. Leadership Psychology: How the Best Leaders Inspire their People. London: Kogan Page; 2014.

18. Noe R. Employee Training and Development (6th ed.). New York, NY: McGraw-Hill; 2013.

19. Pillay S. Your Brain and Business: The Neuroscience of Great Leaders. Upper Saddle, NJ. Pearson Education, Inc.; 2011. 